\title{
Assessing Student Learning in Library Instruction: A Faculty Perspective
}

\author{
Doreen R. Bradley and Jo Angela Oehrli \\ University of Michigan, USA
}

\begin{abstract}
Introduction
Assessing library impact on student learning is essential for demonstrating libraries' integrated value and commitment to higher education. Librarians value this commitment and seek measures of their contributions to higher education. Librarians at the University of Michigan Library taught 808 curriculumrelated sessions to 20,780 students in the academic year from September 1, 2017 through April 15, 2018. In order to measure course instructors' impressions of this instruction, an online survey was designed and conducted to assess student learning in one-time, course-integrated library instruction sessions. The goal of this study was to investigate course instructors' perceptions of student learning from these sessions. The results clearly demonstrate the value that library instruction can bring to the student learning experience. The concepts and skills taught through library instruction are foundational and intrinsic to curricula throughout higher education.
\end{abstract}

\section{Literature Review}

There have been many studies concerning course instructors' perceptions of information literacy as a whole, most significantly work done in the UK by Sheila Webber, Stuart Boon, and Bill Johnston. ${ }^{1}$ Webber, Boon, and Johnston have also studied how course instructors connect the relationship of information literacy to the work in their academic disciplines. The course instructors in these studies indicate that finding sources and teaching students higher order thinking skills are two highly important information literacy skills. Laura Saunders' extensive survey of course instructors in a multitude of disciplines indicates that course instructors do value information literacy as a learning outcome. ${ }^{2}$ Many other studies have reported that course instructors have a low assessment of their students' information literacy skills. These issues are complex and multifaceted. If course instructors believe all three of these documented claims, (1) that course instructors value information literacy, both as a whole and within their own disciplines, (2) that they also believe that students have low information literacy skills, and (3) that information literacy is an important learning outcome, the question then becomes do they also believe that academic library instruction is meeting their course learning outcomes? The goal of our research intends to answer the question of what students are learning in our sessions and whether library instruction at the University of Michigan is meeting course learning outcomes.

\section{Methodology}

Librarians developed a very brief survey with questions focused on how well library instruction sessions met the course instructors' learning outcomes, if students were better able to complete course projects, and to identify what specific concepts and skills students learned. The instrument contains three Likert-scale questions and two open-ended questions (Appendix 2). The survey instrument was designed and administered using Qualtrics. The U-M Library uses a locally designed system called the Scheduling App for Library Instruction (SALI) to manage requests for instruction and also to record statistics. Email addresses were obtained from SALI for all course instructors who requested a library session from September 1, 2017, through April 15, 2018. Several instructors had left the university, so their names were removed. If course instructors requested multiple sessions over the 2017-18 academic year, duplicate email addresses were removed so each course instructors received only one survey, recognizing that instructors would be less likely to complete multiple surveys. The survey was sent to a total of 393 instructors. Survey responses were collected from April 3, 2018, through May 8, 2018, to allow course instructors to evaluate student work at the end of the semester. One reminder message was sent to course instructors who did not respond to the first survey request. A total of 171 surveys were completed. This figure represents a return rate of 43.5 percent.

Librarians analyzed the data from the Likert-scale questions and one of the open-ended questions, "Please comment on concepts or skills that your students learned during this session." Data from the second open- 
ended question revealed that the question was too vague and did not yield useful responses. To analyze the qualitative data generated by the first open-ended question, librarians developed a codebook of likely student learning outcomes based on typical lesson plans. A sample of ten surveys were each coded by two librarians in order to establish inter-rater reliability and develop consistency in the application of codes. All 171 surveys were then divided equally between the two librarians for coding. Data was coded and analyzed using Dedoose.

\section{Results}

Responses to the survey reflect a wide variety of disciplines across campus as well as introductory level courses through graduate level programs. Of the 171 surveys completed, 70 represent social sciences courses, 63 are from arts/humanities courses, 19 are from health sciences, 10 are from engineering/architecture, and 9 represent the sciences. Overall, these figures are quite well reflective of the distribution of disciplines for which library instructors generally teach in a given year. Regarding course level, 51 represent 100-level courses, 24 are from 200-level courses, 38 from 300-level courses, 23 from 400-level courses, and 34 from graduate level courses. These figures represent higher response rates from 300-, 400-, and graduate level courses than are generally represented in the overall distribution for which library instructors teach. Library instructors typically teach for more 100- and 200-level courses as a percentage of total instruction. Thoughts about this difference in response rate are included in the limitations section of this paper. With such high response rates from courses at all levels, and graduate level courses in particular, the data provide excellent insight into the nature of instruction commonly occurring across the spectrum of curricula in our schools and colleges.

\section{General Satisfaction}

Survey recipients were given three statements to respond to on a five-point Likert Scale (Strongly Agree, Agree, Neutral, Disagree, Strongly Disagree).

1. Students were better able to complete coursework because of this session.

2. The instruction session met my learning goals and expectations.

3. I would recommend library instruction to other instructors.

Responses were overwhelmingly positive to all three statements. One hundred sixty-nine recipients responded to the first question regarding the relationship between the library session and completion of student coursework. One hundred sixty responded either Strongly Agree (115) or Agree (45). Nine responded Neutral. There were no Disagree or Strongly Disagree responses. There were 170 responses to the question about meeting course instructors' learning goals and expectations. One hundred thirty-eight course instructors responded Strongly Agree and 30 responded Agree. Two respondents chose Neutral. Again, there were no respondents who chose Disagree or Strongly Disagree. Finally, the third statement regarding recommended library instruction to other instructional course instructors had a similar pattern. One hundred seventy-one recipients participated in this question with a vast majority responding in a positive manner (Strongly Agree=152, Agree=17). There were two Neutral responses and no Disagree or Strongly Disagree responses.

At first glance, with no negative responses, one might question the survey's design or pool of recipients. It is important to note that there was no evaluation of survey recipients prior to dissemination of the survey regarding course instructors' levels of satisfaction. The survey was released to all current academic instructors that had some record of library instruction during the time allotted. In addition, the library has conducted similar surveys over the past five years that did include negative responses from respondents, so there is little reason to believe that course instructors censored their opinions on this particular instruction survey. 
A closer look at the nine neutral responses to "Students were better able to complete coursework because of this session," revealed that there were two responses assigned the Library Instructor Compliment code. Within the text of another response, the collection was complimented. Other patterns emerge from these responses, although the researcher should be careful about drawing major conclusions from such a small group (9). Five of the nine neutral responses were from arts and humanities classes. Of those five, only one class was a 100-level course. Seven of the nine neutral responses to this statement were from courses designated at the 300 level or above. This information will be shared with the librarians who teach upper level courses just as information to consider while designing lesson plans/learning outcomes in the future. The neutral responses to the other two statements ( 2 each) were not analyzed due to the low response in this part of the scale. Two responses are not enough upon which to base any conclusions.

\section{Overview of Code Application for Learning Outcomes}

Librarians coded for the question, "Please comment on concepts or skills that your students learned during this session." The data yield many interesting trends and insights that aid library instructors in understanding how their teaching integrates into programs across the university. Use of these codes varies greatly by discipline and by level of course as one might expect based on the needs of students in different disciplines at various points in their programs. In fact, the data and resulting observations are very intertwined by these two variables. To present the data in a cohesive manner, the results are discussed by individual code, with an analysis of the use of that specific code by discipline and course level together in order to demonstrate patterns within and across curricula. The codebook designed for this analysis contains 23 codes. Most of the codes relate directly to topics generally covered in information literacy instruction, such as finding and evaluating sources. Librarians also coded for a few additional items, such as "Library Instructor Compliment" where a specific library instructor was mentioned, data instruction, and a variety of technology tools such as web design and blog writing. All 23 codes were used a least once. The most frequently used codes are: Finding Sources n=91, Evaluating Sources n=50, Library Organization (physical library and website) $n=34$, Search Strategy Development $n=31$, and Using and Understanding Sources n=27. Specific tools and databases were noted in $\mathrm{n}=16$ of the sessions. The next most frequently used codes were Nature of Information and Primary Sources, which were both coded for 12 sessions, and Data Instruction, which was coded 11 times. Library Instructor Compliment was coded 16 times. While each individual technology code was not used frequently, the technology codes combined were used 16 times. See Appendix 1 for all code frequency applications.

\section{Code Analysis by Discipline and Course Level}

In this section, analysis of the five most frequently used codes as well as codes that reveal unexpected findings are presented. As one might expect, the most frequently used code, Finding Sources, was used fairly equally across all disciplines and all levels of courses as demonstrated in Figure 1. However, upon further examination of course levels within identified disciplines, certain patterns emerge. Most disciplines demonstrate decreasing focus on Finding Sources as course level increases, yet health sciences illustrate the opposite pattern of increasing emphasis on Finding Sources as course levels increase (Figure 2). The second most frequently used code, Evaluating Sources, also demonstrates interesting patterns. This topic is taught in a fairly distributed manner throughout the health sciences and social sciences. In the other disciplines, it peaks in 100-level courses and shows a very rapid decline in advanced courses. The topic of Library Organization appears throughout the disciplines with the exception of science courses where it only appears in 100-level courses. Search Strategy Development, the fourth most used code, is well represented across the social sciences and arts/humanities disciplines. It peaks in graduate level health sciences, only appears in the 200 level in engineering/architecture, and again, only features in 300-level sciences. Using and Understanding Sources, the last of the top five codes used, is reflected in most levels of courses in the arts/humanities, sciences, and social sciences. Interestingly, Using and Understanding Sources does not appear in graduate level courses in the sciences or social sciences, while conversely, it only appears in graduate level courses for the health sciences or engineering/architecture.

Several lesser used codes also demonstrate interesting patterns. Students learned about the Nature of Information in a variety of social sciences and arts/humanities sessions across course levels. For science 
courses, it was noted only in 300-level courses, and it did not factor into any instruction in engineering/architecture or health sciences. Course instructors report that their students learned about primary sources throughout various levels of arts/humanities and social sciences courses but not in a single science or health sciences course.

\section{Concurrent Learning Outcomes}

Librarians analyzed codes to understand which concepts are often learned together in a single instruction session. Unsurprisingly, the two topics that most often occur in the same workshops are Finding Sources and Evaluating Sources (co-occurrence=25). Finding Sources co-occurs with three other topics frequently as well: Search Strategy Development (21), Library Organization (17), and Primary Sources (9). Looking closely at this data and comparing the results to a common understanding of course instructors and course needs, a library instructor would probably conclude that finding sources goes hand-in-hand with understanding how the library is organized, how to create a good search strategy, and how to evaluate what you find, including recognizing primary sources. The data in this analysis are reassuring in that concepts that librarians expect to be taught together are in fact being learned by students during the same instruction session.

\section{Unexpected Findings}

There are a number of unexpected findings in the survey data. One such finding is in the application of the code for Academic Integrity. This code appears exclusively in 100-level courses, and $80 \%$ of the time in arts/humanities courses with the remaining $20 \%$ occurring in social sciences courses. Why do course instructors not report Academic Integrity in upper level courses? Based upon librarian knowledge of lesson plans, this topic is definitely taught in upper level courses. Citing Sources, as a code, does not appear in any health sciences or sciences courses and only in graduate level engineering/architecture courses. It is better distributed throughout social sciences and arts/humanities courses. Course instructors report students learned about obtaining Future Help only in 400-level and graduate level courses regardless of discipline.

\section{Discussion}

The data collected and analyzed from this survey of course instructors reinforces much of what library instructors believe about our information literacy program. For the most part, the data match what instructors are teaching and hope students are learning. This feedback from course instructors validates the assumptions that library instructors make about their teaching. For example, the top five used topic codes are reflective of our teaching practices. Finding Sources and Evaluating Sources are vital elements of the vast majority of library instruction sessions and, according to this data, they are often taught together. It is rewarding to see that course instructors believe students learned these concepts well during these sessions. Likewise, Library Organization and Search Strategy Development are highly recognized as learning outcomes.

Using charts, graphs, and other data visualizations truly aid in identifying overall patterns throughout the disciplines and course levels. Having these patterns, they can be combined with library instructor expertise about what was taught and ideally what students should be learning in order to identify gaps as well as strengths of our teaching. For example, one gap that is readily apparent is the low frequency with which the code Future Help is applied. Using knowledge of teaching patterns, it is well documented through lesson plans that Future Help is a concept taught in almost every instruction session. This would hold true for traditional sessions on research instruction as well as technology sessions. So, why do course instructors report that their students so infrequently learned about getting Future Help? Perhaps because this is not a learning outcome that course instructors prioritize or they do not place as much importance on it as library instructors do. Still, it is making instructors pause and examine whether we need to address this differently during our sessions. Equally perplexing are the findings regarding use of the codes Search Strategy Development and Finding Sources. Upon further exploration, it makes complete sense that these concepts appear in upper level health sciences courses because library instructors are frequently asked to teach about conducting systematic reviews. Advanced skills in finding sources and devising excellent search strategies are naturally part of the skill in conducting systematic reviews. Still, it is making instructors pause and examine whether we need to address the concepts differently during our sessions in other disciplines. 
It is rewarding to learn that course instructors overwhelmingly state that library instructors are helping students to complete coursework better, meeting learning goals and expectations, and that course instructors would recommend library instruction to other instructors. We will make sure that librarians who teach upper level workshops are aware that, in a small number of cases, course instructors may not feel strongly that library instruction is helping students complete coursework better. Even so, that small portion of responses does not negate the phenomenal conclusion that course instructors think library instructors are enhancing the classroom experience and necessary knowledge is being acquired by students.

\section{Limitations}

There are two main limitations to this study which require careful examination. Since response to the survey instrument was voluntary, course instructors chose whether or not to respond. Course instructors of 100level courses may have responded only once even if they taught multiple sections of a course where they had requested library instruction. Course instructors of 100-level courses are frequently Graduate Student Instructors (GSIs), and their teaching patterns are more varied than tenure-track faculty or instructors with longer teaching appointments. Often, they teach one semester, but perhaps not the subsequent semester. They may be less invested in teaching and less likely to respond. Instructors of upper level courses may have longer-term relationships with the library instructors who teach for them, and thus be more likely to respond particularly for upper level courses. This factor could explain why we have such high response rates from instructors of upper level undergraduate and graduate courses. Another limitation is that the study relies on the memory and impressions of course instructors as to what they believe their students learned during the instruction sessions. Ideally, surveying students' as well as course instructors' opinions on learning would present a more complete set of data from which to draw conclusions.

\section{Conclusions}

According to our literature review, course instructors value information literacy and believe that their students generally have low information literacy skills. Course instructors want information literacy to be a learning outcome. It is encouraging to conclude from this study that, in most cases, librarians are meeting these information literacy outcomes. Students are learning the concepts and skills they need to be academically successful in their courses. The outcomes of this study lead to the questions of what it means for course instructors who do not request instruction. How might we use these survey results to market library instruction to those course instructors who do not currently include such instruction in their courses? The data and conclusions drawn from this study will be used to encourage additional course instructors to integrate library instruction into courses that require research or technology skills for student work.

-Copyright 2019 Doreen R. Bradley and Jo Angela Oehrli

\section{Endnotes}

1. Webber, Boon, and Johnston, "A Phenomenographic Study"; Webber, Boon, and Johnston, "A Comparison of UK Academics' Conceptions."

2. Saunders, "Faculty Perspectives on Information Literacy."

\section{Bibliography}

Boon, Stuart, Sheila Webber, and Bill Johnston. "A Phenomenographic Study of English Faculty's Conceptions of Information Literacy.” Journal of Documentation 63, no. 2 (March 13, 2007): 204-28. https://doi.org/10.1108/00220410710737187.

Saunders, Laura. "Faculty Perspectives on Information Literacy as a Student Learning Outcome." The Journal of Academic Librarianship 38, no. 4 (2012): 226-36. http://dx.doi.org/10.1016/j.acalib.2012.06.001.

Webber, Sheila, Stuart Boon, and Bill Johnston. "A Comparison of UK Academics' Conceptions of Information Literacy in Two Disciplines: English and Marketing." Library and Information Research 29, no. 93 (2005): 4-15. 
Figure 1-Finding Sources code used by discipline

Set: Course Demographics, Field: Discipline

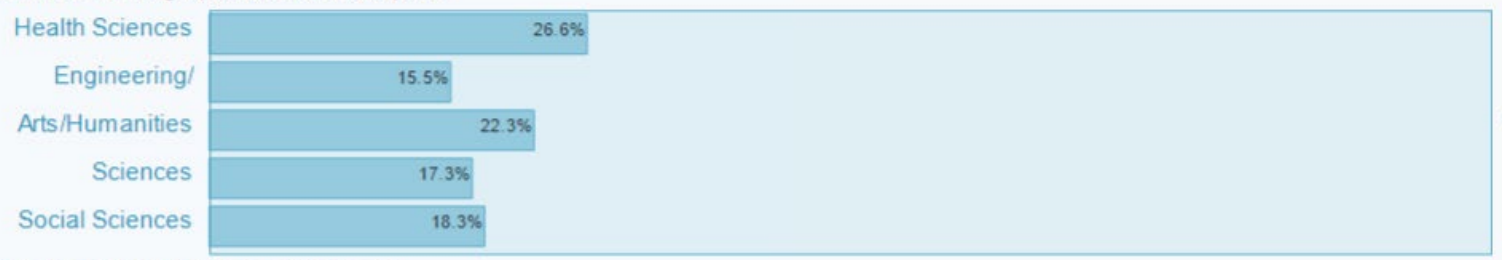

Set: Course Demographics, Field: Level

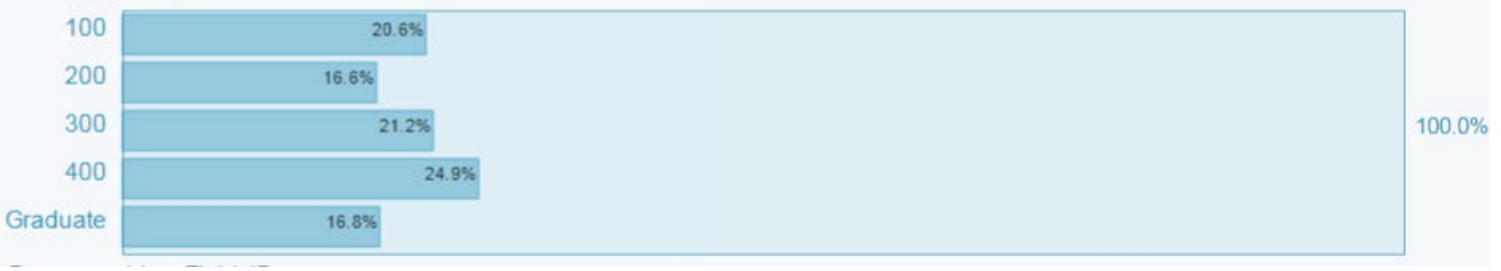

Figure 2-Finding Sources code used by discipline and course level

Descriptor $\mathrm{x}$ Descriptor $\mathrm{x}$ Code

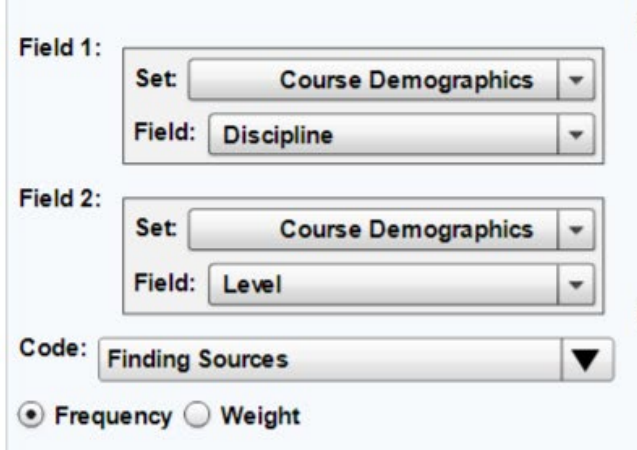

Health Sciences

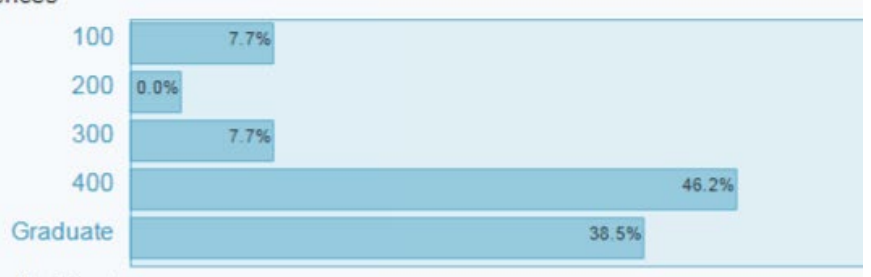

Engineering/Architecture

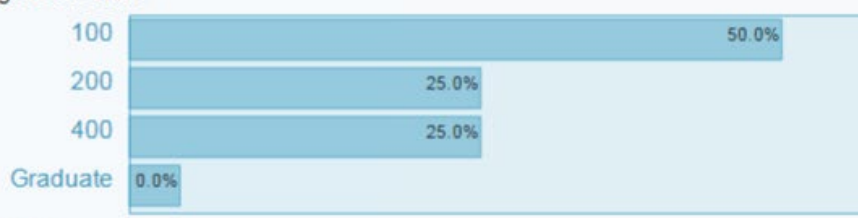

Arts/Humanities

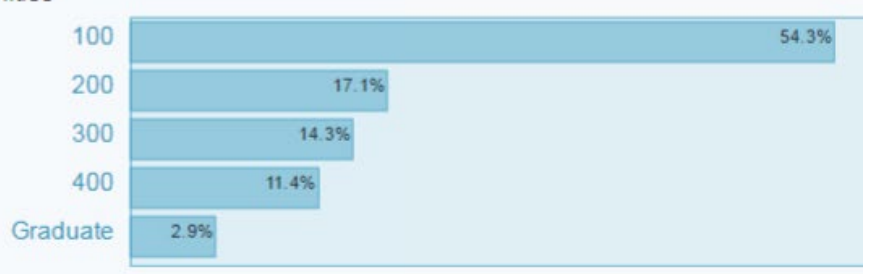

Sciences

\begin{tabular}{r|rr} 
& & $50.0 \%$ \\
300 & & $50.0 \%$ \\
400 & $0.0 \%$ & \\
Graduate & $0.0 \%$ & \\
\cline { 2 - 3 } & &
\end{tabular}


Appendix 1: Code Descriptions

\begin{tabular}{|c|c|}
\hline Code & Description \\
\hline Nature of Information & $\begin{array}{l}\text { How information is organized in a "big picture" manner. "Big } \\
\text { picture" = How information is produced; Who owns } \\
\text { information; The information cycle; etc. }\end{array}$ \\
\hline Library Organization & $\begin{array}{l}\text { How UM Library is organized either physically or virtually. This } \\
\text { would also include when users are introduced to the library and } \\
\text { when an overview of the library or library website is mentioned. }\end{array}$ \\
\hline Topic Exploration & $\begin{array}{l}\text { How a researcher decides on what to study or what to write } \\
\text { about (topic) }\end{array}$ \\
\hline Search Strategy Development & $\begin{array}{l}\text { How a student decides the method/manner in which to search } \\
\text { including keywords and limiting searches }\end{array}$ \\
\hline Finding Sources & $\begin{array}{l}\text { Generic code to be used when the instructor writes that their } \\
\text { students learned to find sources/materials for a paper/project }\end{array}$ \\
\hline Primary Sources & $\begin{array}{l}\text { Intentionally teaches that there is a difference between primary } \\
\text { and secondary sources. The word primary is used in this code. }\end{array}$ \\
\hline Evaluating Sources & $\begin{array}{l}\text { Explicitly states that evaluating sources is taught. This is when a } \\
\text { more introductory or "surface" level of evaluation is taught } \\
\text { and/or mention is made of choosing between sources. Also, } \\
\text { other terms that might indicate evaluating sources would } \\
\text { include mention of critical thinking around sources, } \\
\text { scholarly/non-scholarly, peer review. }\end{array}$ \\
\hline Using and Understanding Sources & $\begin{array}{l}\text { Beyond evaluating sources, this code is used when the content } \\
\text { includes an actual discussion about what the learner should do } \\
\text { with the source and how the learner should incorporate the } \\
\text { information in that source into their own knowledge/project. } \\
\text { Text that answers the question, "Can I use this source?" might } \\
\text { also be incorporated in this code. }\end{array}$ \\
\hline Citing Sources & $\begin{array}{l}\text { Explicit instruction about citing sources. When coding for } \\
\text { Citation Management Instruction, this code should also be } \\
\text { applied. }\end{array}$ \\
\hline Future Help & $\begin{array}{l}\text { Getting follow up assistance. This may include an explicit } \\
\text { mention of Ask a Librarian virtual reference in this context. }\end{array}$ \\
\hline
\end{tabular}




\begin{tabular}{|c|c|}
\hline Code & Description \\
\hline Blog Instruction & $\begin{array}{l}\text { How to use any blog tool. If a specific tool is mentioned, also } \\
\text { code for "Tools"." }\end{array}$ \\
\hline Video Tool Instruction & $\begin{array}{l}\text { How to use any video creation tool. If a specific tool is } \\
\text { mentioned, also code for "Tools." }\end{array}$ \\
\hline Photoshop Instruction & $\begin{array}{l}\text { How to use Photoshop. Since Photoshop is mentioned, } \\
\text { specifically code for "Tools" as well. }\end{array}$ \\
\hline Web Design Instruction & $\begin{array}{l}\text { How to create a website. If a specific tool is mentioned, also code } \\
\text { for "Tools." }\end{array}$ \\
\hline Citation Management Instruction & $\begin{array}{l}\text { How to use bibliographic management tools. If a specific tool is } \\
\text { mentioned, also code for "Tools." }\end{array}$ \\
\hline Wikipedia Instruction & How to create/edit Wikipedia articles \\
\hline Poster Design Instruction & $\begin{array}{l}\text { How to create a poster. If a specific tool is mentioned, also code } \\
\text { for "Tools." }\end{array}$ \\
\hline Tools & $\begin{array}{l}\text { Specific databases, data sources (like census data, or a mapping } \\
\text { tool) is mentioned. }\end{array}$ \\
\hline Academic Integrity & $\begin{array}{l}\text { Instruction included plagiarism and other academic integrity } \\
\text { concepts. Look closely at anything coded "Citing Sources" before } \\
\text { automatically adding this code. }\end{array}$ \\
\hline Data Instruction & $\begin{array}{l}\text { How to find data, how to think about the data you find, data } \\
\text { visualization, etc. }\end{array}$ \\
\hline Library Instructor Compliment & $\begin{array}{l}\text { Respondent explicitly mentions something that the library } \\
\text { instructor did well }\end{array}$ \\
\hline Special Collections & $\begin{array}{l}\text { Explicit mention of instruction around Special Collections, } \\
\text { archives, manuscripts, etc. }\end{array}$ \\
\hline
\end{tabular}




\begin{tabular}{|l|l|}
\hline Code & Description \\
\hline Other & $\begin{array}{l}\text { This code is used when the other codes do not apply, yet the } \\
\text { coder feels that there is valuable information conveyed in the } \\
\text { text. Those texts that are assigned this code will be examined } \\
\text { holistically to find patterns within them and also provide an } \\
\text { opportunity to redistribute texts with the "Other" code into } \\
\text { other categories. }\end{array}$ \\
\hline
\end{tabular}

Appendix 2: Survey Instrument

In fall 2017 or winter 2018, a librarian taught an instruction session for one of your courses. We are assessing student learning during these sessions. Your feedback is critical in understanding what concepts and skills students may be learning and if they apply this knowledge. Thank you for taking the time to complete this quick survey.

Please enter the course number(s) for which you had a library session (e.g., English 125, Psych 303):

Thinking back to the instruction session for your course and feedback from students since the session, please mark the appropriate column for each question below.

\begin{tabular}{|l|l|l|l|l|l|}
\hline & $\begin{array}{l}\text { Strongly } \\
\text { Agree }\end{array}$ & Agree & Neutral & Disagree & $\begin{array}{l}\text { Strongly } \\
\text { Disagree }\end{array}$ \\
\hline $\begin{array}{l}\text { Students were better } \\
\text { able to complete } \\
\text { coursework because of } \\
\text { this session. }\end{array}$ & & & & & \\
\hline $\begin{array}{l}\text { The instruction session } \\
\text { met my learning goals } \\
\text { and expectations. }\end{array}$ & & & & & \\
\hline $\begin{array}{l}\text { I would recommend } \\
\text { library instruction to } \\
\text { other instructors. }\end{array}$ & & & & & \\
\hline
\end{tabular}

Please comment on concepts or skills that your students learned during this session.

Please comment on how you think the session did or did not affect the quality of student work in your course. 